\title{
Protective role of murine norovirus against Pseudomonas aeruginosa acute pneumonia

\author{
Marion Thépaut ${ }^{1}$, Teddy Grandjean ${ }^{1}$, Didier Hober ${ }^{2}$, Pierre-Emmanuel Lobert ${ }^{2}$, Perrine Bortolotti ${ }^{1}$, Karine Faure ${ }^{1}$, \\ Rodrigue Dessein ${ }^{1}$, Eric Kipnis ${ }^{1}$ and Benoit Guery ${ }^{1 *}$
}

\begin{abstract}
The murine norovirus (MNV) is a recently discovered mouse pathogen, representing the most common contaminant in laboratory mouse colonies. Nevertheless, the effects of MNV infection on biomedical research are still unclear. We tested the hypothesis that MNV infection could alter immune response in mice with acute lung infection. Here we report that co-infection with MNV increases survival of mice with Pseudomonas aeruginosa acute lung injury and decreases in vivo production of pro-inflammatory cytokines. Our results suggest that MNV infection can deeply modify the parameters studied in conventional models of infection and lead to false conclusions in experimental models.
\end{abstract}

\section{Introduction}

The first murine norovirus, MNV1, was isolated in 2003 from the brain of an immunocompromised mouse lacking recombination-activating gene two and signal transducer and activator of transcription one (RAG2/STAT1 ${ }^{-1-}$ ) [1]. Murine noroviruses are non-enveloped, positive-strand RNA viruses that belong to the Norovirus genus in the Caliciviridae family. This virus is related to the human norovirus which is estimated to be responsible for up to $90 \%$ of nonbacterial epidemic gastroenteritis worldwide [2]. Like human norovirus, many strains of MNV have been isolated and biological diversity among MNV strains has also been reported [3-7]. Strains can either be rapidly cleared in wild type animals like MNV-1 CW1, CW3, and WU11, while CR1, CR3, CR6, CR7 and S99 have been published to be persistent $[4,5]$.

Today, murine norovirus is the most prevalent virus in research mouse colonies [8]. In North America, 22.1\% of 12,639 mouse sera were positive for anti-MNV-1 antibodies [9]. This high prevalence was confirmed by a serological survey in Europe [10]. Similar prevalence rates were observed in Japan and South Korea after serological or RT-PCR analysis of murine samples [11-13]. This worldwide high prevalence provides a tremendous potential for this virus to interfere with mouse models of

\footnotetext{
* Correspondence: bguery@gmail.com

${ }^{1}$ EA 7366: Pseudomonas aeruginosa Host-Pathogen Translational Research Group, UDSL, Université Lille Nord de France, 59045 Lille, France Full list of author information is available at the end of the article
}

diseases. However, the effects of MNV infection on biomedical research are still unclear.

Some studies showed that norovirus had no effect on specific animal models. Hensley et al. have shown that murine norovirus CR6 infection had no significant effect on adaptive immunity to vaccinia virus or influenza A virus [14]. Similarly, transient MNV 1 or persistent MNV4 norovirus infection did not alter the pathology of Salmonella typhimurium induced intestinal inflammation and fibrosis in mice [15]. In another model, infection with murine norovirus 4 did not alter helicobacter-induced inflammatory bowel disease in interleukin $10^{-/}$mice [16].

However, several other studies showed potential consequences of norovirus infection. Lencioni et al. found that MNV infection could accelerate bacteria-induced inflammatory bowel disease progression in $\mathrm{Mdrla}^{-1-}$ but not with $\mathrm{Smad}^{-1-}$ mice [17]. Murine norovirus-1 was also reported to promote inflammation and mortality in mice superinfected with Escherichia coli [18].

To better understand the impact of MNV infection in animal models of bacterial pathogenicity, we investigated the effect of the MNV S99 strains on a Pseudomonas aeruginosa induced lung injury model in C57BL/6 mice. Co-infections may have unpredictable consequences with alterations of the host immune response and potentially mislead the investigator in the pathophysiological hypothesis based on the results. This study indicates that MNV-induced immunomodulation increases survival and decreases in vivo production of pro-inflammatory 
cytokines. These phenomena are a direct consequence of MNV infection and compromise the result obtained in $P$. aeruginosa studies.

\section{Materials and methods Mouse model}

Wild-type C57BL/6 male mice, 8 to 10 weeks old, were purchased from Janvier laboratories. The mice had free access to a standard laboratory food diet in a half-day light cycle exposure and temperature. Mice were housed in a controlled Specified Pathogen Free (SPF) environment as determined by the FELASA recommendations, in either a static micro-isolator or individually ventilated cages. Vendor reports indicated mice were negative for murine norovirus. All animal studies were approved by the investigational review board of the Nord-Pas-de-Calais. All animal experiments were performed in an accredited establishment ( $\mathrm{N}^{\circ}$ B59-108) according to the governmental guidelines $\mathrm{N}^{\circ} 86 / 609 / \mathrm{CEE}$.

\section{Cell lines}

Raw264.7 cells (ATCC TIB-71) purchased from the European Collection of Cell Cultures (ECACC) (Sigma-Aldrich, L'isle d'Abeau Chesnes, France) were maintained in Dulbecco's Modified Eagle Medium, high glucose, GlutaMAX $^{\mathrm{m}}$ Supplement, pyruvate (DMEM) supplemented with $10 \%$ heat inactivated fetal bovine serum (Gibco).

\section{Virus stocks and plate assays}

All experiments were performed with Murine Norovirus S99 (Berlin/2006/DE) purchased from the FriedrichLoeffler Institut (Greifswald-Insel Riems, Deutchland). Virus stocks were generated using Raw264.7 as described previously [19]. To generate a virus stock, viral suspensions were concentrated with Amicon Ultra-15, PLHK Ultracel-PL Membrane, 100 kDa (Merck Millipore). MNV titer was obtained by endpoint titration as described previously and expressed as TCID50/ml according to the Spearman-Kärber method [20,21]. The theoretical relationship between TCID50 and plaque forming units (PFU) is approximately 0.69 by applying the Poisson distribution [22].

\section{Bacterial strain}

All experiments were performed with Pseudomonas aeruginosa strain CHA (CHA) provided by B. Toussaint (THeREx, Grenoble, France). A single colony was inoculated into Luria Bertani (LB) media and grown overnight at $37^{\circ} \mathrm{C}$ with shaking. The day of the infection, a $1 / 40$ dilution of the overnight culture was prepared and incubated $2 \mathrm{~h}$ at $37{ }^{\circ} \mathrm{C}$ with shaking. Bacteria were washed twice with sterile phosphate-buffered saline (PBS). The bacterial pellet was resuspended in PBS and optical density was measured at $A_{600}$, the desired infectious dose was extrapolated from a standard growth curve. Bacterial suspensions and inoculum standardization were then determined based on spectrometry and verified by serial dilution and plating on bromocresol purple agar (BCP; bioMérieux, Marcy l'Étoile, France).

\section{Mouse infection pneumonia}

C57BL6/J mice were infected by oral gavage with $1.10^{7}$ PFU of MNV S99, control mice received PBS. Seven days later, a pulmonary infection model was induced by intranasal instillation of $P$. aeruginosa. Mice were lightly anesthetized with inhaled sevoflurane (Forene Abbott, Queensborough, Kent, United Kingdom), after which $40 \mu \mathrm{L}$ of the bacterial solution were administered intranasally representing a total of $2.10^{6} \mathrm{CFU} /$ mouse (except for survival studies conducted with lethal inoculate of $5.10^{6} \mathrm{CFU} /$ mouse). Control mice received $40 \mu \mathrm{L}$ of PBS. All mice were sacrificed at $24 \mathrm{~h}$ (except for survival studies, mice were monitored on weight and clinical score $96 \mathrm{~h}$ post bacterial infection).

\section{Clinical score}

The evolution of the disease score assessing the clinical appearance of the animals was evaluated on 4 items scored from 0 to 10 summarized in Table 1 (body temperature, appearance of the bristle, behaviour and weight loss; 0 : healthy mice, 10 moribund mice $)$. Clinical score $=[($ Fur score + temperature score + movement score $)+(\%$ weight $\operatorname{loss} /(-5))]$.

\section{Lung injury}

Alveolo-capillary membrane permeability was evaluated by measuring Fluoresceine Isothiocyanate labeled (FITC)albumin leakage from the vascular compartment to the alveolar-interstitial compartment, as previously described [23]. Briefly, mice were sacrificed after FITC-albumin injection, blood and bronchoalveolar lavage was collected. The fluorescence ratio measured in serum and bronchoalveolar lavage (Excitation: $487 \mathrm{~nm}$, Emission: $520 \mathrm{~nm}$; Mithras LB 940, Berthold Technologies, Bad Wildbad, Germany) reflects alveolo-capillary permeability.

\section{Bronchoalveolar lavage (BAL)}

Lungs from each experimental group were washed with a total of $1.5 \mathrm{~mL}$ PBS. The recovered lavage fluid was centrifuged ( $200 \mathrm{~g}$ for $10 \mathrm{~min}$ ), the cellular pellet was washed twice with PBS. BAL samples were frozen at

Table 1 Clinical score evaluation

\begin{tabular}{llll}
\hline Score & Movement & Fur & Temperature \\
\hline 0 & Moving & Smooth & Normal \\
1 & Low mobility & & \\
2 & Prostrate & Bristly & Cold \\
\hline
\end{tabular}


$-80{ }^{\circ} \mathrm{C}$ after collection for cytokine measurement. Cell counts were performed directly by optical microscopy. Cell monolayers were prepared with a cytocentrifugator and stained with a Wright-Giemsa stain. Cellular types were obtained by counting 200 cells/sample and expressing each type of cell as a percentage of the total number counted.

\section{Bacterial burden}

Mouse lungs and spleens were homogenized in sterile containers with PBS. Lung and spleen homogenates were sequentially diluted and cultured on bromocresol purple agar plates for $24 \mathrm{~h}$ to assess bacterial load.

\section{Measurement of cytokines}

Mouse cytokines, IL- 6 and TNF- $\alpha$ were measured in culture or BAL supernatant using enzyme-linked immunosorbent Assay (ELISA) kits from Peprotech.

\section{Statistical analysis}

Statistical analysis was carried out using Prism 5 software (Graph-Pad Software, San Diego CA). Values are expressed as mean \pm SEM. Comparison groups were analysed with the nonparametric Mann-Whitney test. Survival curves were analysed using Log-rank (MantelCox) test. Significance was accepted at ${ }^{*} p<0.05 ;{ }^{* *} p<$ $0.01 ; * * * 0.001$.

\section{Results}

Murine norovirus infection increases survival of mice with $P$. aeruginosa induced lung injury

To determine whether an established infection with MNV affected $P$. aeruginosa infection, survival was analysed for $96 \mathrm{~h}$. After 7 days of colonisation with the virus, mice were infected by intranasal instillation of $P$. aeruginosa. No mortality was observed for two control groups PBS/PBS and MNV/PBS. A dose of $5.10^{6} \mathrm{CFU}$ of
P. aeruginosa induced $100 \%$ lethality in the PBS/CHA group. Infection with MNV before $P$. aeruginosa was associated to a $40 \%$ survival (Figure 1).

\section{Murine norovirus infection decreases $P$. aeruginosa induced lung injury and dissemination}

A dose of $2.10^{6}$ CFU of $P$. aeruginosa was inoculated and all the analyses were performed at $24 \mathrm{~h}$ after the bacterial challenge. Control groups, PBS/PBS and MNV/ PBS, showed no body weight change and a normal clinical score. In $P$. aeruginosa infected mice, body weight significantly decreased and the clinical score significantly increased compared to the PBS/PBS group. MNV pre infection did not prevent body weight decrease but significantly reduced the clinical score compared to $\mathrm{PBS} / \mathrm{CHA}$ mice (Figures $2 \mathrm{~A}$ and $\mathrm{B}$ ).

Regarding lung alveolar capillary permeability at $24 \mathrm{~h}$, the efflux of the protein tracer in the MNV/PBS group was comparable to the control PBS/PBS group. In PBS/ $\mathrm{CHA}$ infected animals, there was a significant increase of permeability compared to the PBS/PBS group. Mice pre-treated with MNV and further infected with $P$. aeruginosa presented a slight increase of permeability compared to control groups but significantly lower than the PBS/CHA group (Figure 2C).

Total cell counts in BAL were no different in PBS/PBS and MNV/PBS groups. $P$. aeruginosa infection, compared to the PBS/PBS group, induced a significant increase of the total cell count; MNV pre infection significantly decreased this number (Figure 2D). The differential analysis of the cells showed a decreased recruitment of neutrophils and lymphocytes in the MNV/CHA group compared to the PBS/CHA group (Figures $2 \mathrm{E}$ and F).

Lung bacterial loads were not significantly different between $\mathrm{PBS} / \mathrm{CHA}$ and $\mathrm{MNV} / \mathrm{CHA}$ groups. P. aeruginosa infection, compared to the PBS/PBS group, induced significant bacterial dissemination measured by spleen

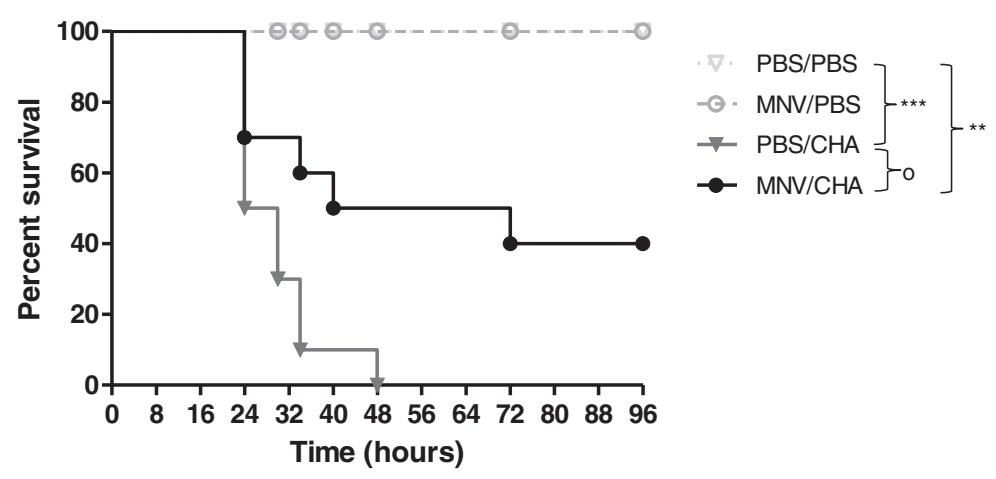

Figure 1 Survival analysis. WT mice were infected per os with 1.107 PFU of MNV or PBS ( $n=10$ /group). A week later, mice were infected with intranasal instillation of $5.10^{6}$ CFU of $P$. aeruginosa or PBS. Lethality was monitored for $96 \mathrm{~h}$ after $P$. aeruginosa infection. ${ }^{*}, P<0.05$ for a comparison with the control PBS/PBS; **, $P<0.01$ for a comparison with the control PBS/PBS; ${ }^{* * *}, P<0.001$ for a comparison with the control PBS/PBS; ${ }^{\circ} P<0.05$ for a comparison with $\mathrm{PBS} / \mathrm{CHA}$. 

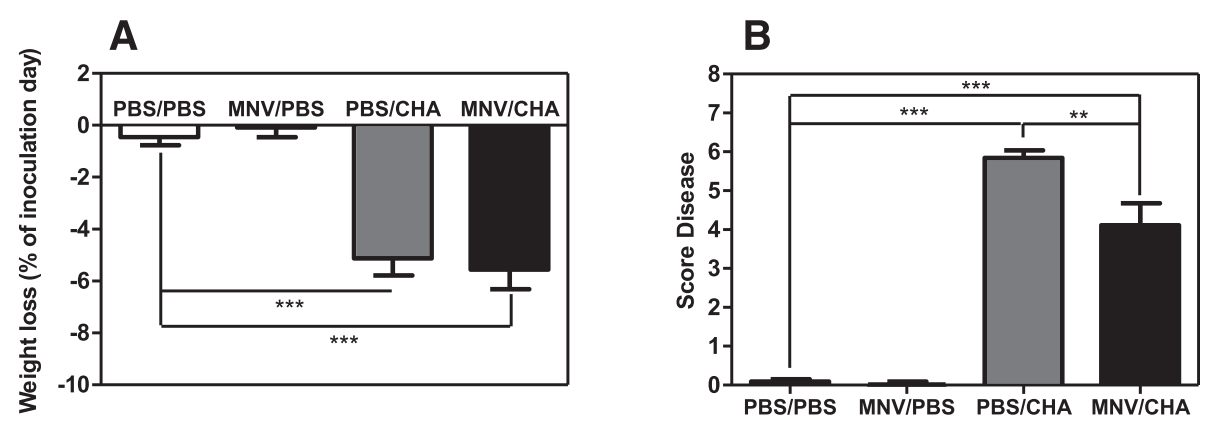

\section{C}
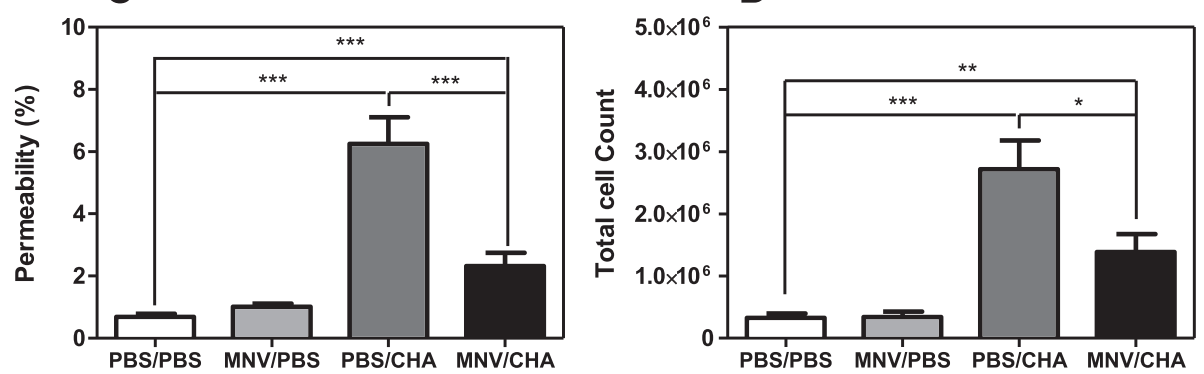

$E$
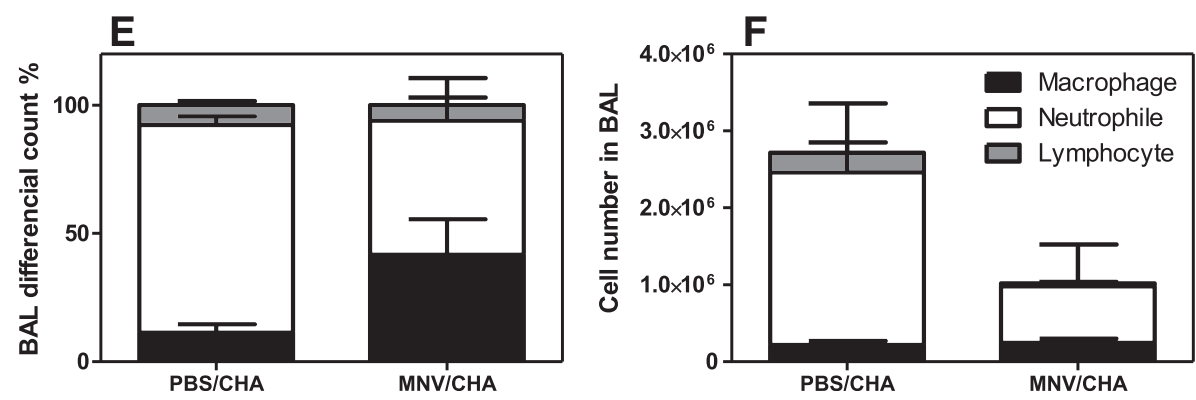

Figure 2 Physiological and alveolar capillary evaluation. WT mice were infected per os with $1.10^{7}$ PFU of MNV or PBS ( $\left.n=10 / g r o u p\right)$. A week later, mice were infected with intranasal instillation of $2.10^{6}$ CFU of $P$. aeruginosa or PBS. Changes in body weight (A) and score diseases (B) were evaluated and mice were sacrificed at $24 \mathrm{~h}$ post-infection. Lung injury was assessed by alveolar capillary barrier permeability (C) and cells from Bronchoalveolar Lavage were counted (BAL) (D-F). ${ }^{*}, P<0.05 ;{ }^{*}, P<0.01 ;{ }^{* *}, P<0.001$.

bacterial load. Moreover, bacterial dissemination was significantly decreased for the MNV/CHA group compared to the PBS/CHA group (Figure 3).

\section{Murine norovirus infection modulates $P$. aeruginosa induced pro-inflammatory response}

We finally analysed the synthesis of TNF alpha and interleukin 6 under the same experimental conditions. No difference in cytokine production was observed between the two control groups PBS/PBS and MNV/PBS. However, the production of these two pro-inflammatory cytokine in response to acute infection was significantly reduced in mice pre exposed to MNV compared to the PBS/CHA group (Figure 4).

\section{Discussion}

Murine norovirus is frequently encountered in research mouse colonies therefore raising the question of its potential influence in mouse models. Recent data show that norovirus target immune cells. Indeed, the murine norovirus is capable of infecting macrophages, dendritic cells and B lymphocytes in vitro as well as in vivo [24-26]. There is evidence of extra-intestinal spread of MNV. The cellular tropism of murine norovirus is known for macrophages and migratory dendritic cells [5], it is possible that norovirus diffuse into the way associated with the cells of organism. This is supported by a recent study in which the depletion of mouse dendritic cells prevents the spread of murine norovirus in mesenteric lymph nodes [27].

MNV displays tropism for myeloid cells and establishes persistent infection without causing obvious disease in immune-competent mice [25]. This tropism for myeloid cells suggests a potential effect on inflammation and the immune responses. For the past few years, most of the studies focused on the interference of MNV on biomedical mouse models of inflammatory bowel disease (IBD). For example, ATG16L1 mice infected with MNV 
A

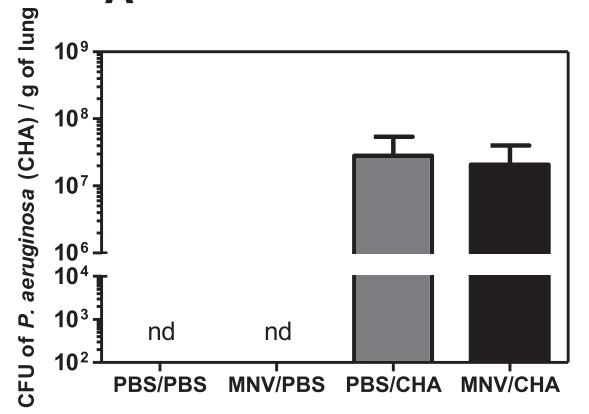

B

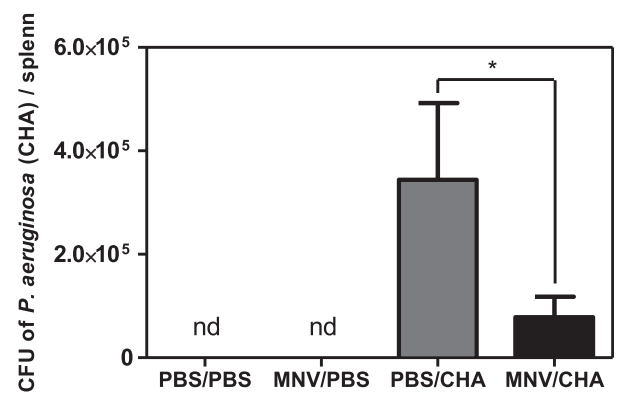

Figure 3 Microbiological parameters. WT mice were infected per os with $1.10^{7}$ PFU of MNV or PBS ( $\left.n=10 / g r o u p\right)$. A week later, mice were infected with intranasal instillation of $2.10^{6}$ CFU of $P$. aeruginosa or PBS. Bacterial load in the lungs $(\mathbf{A})$ and dissemination (B) assessed through spleen or cultured lung homogenate. ${ }^{*}, P<0.05$; $^{* *}, P<0.01$; ${ }^{* *}, P<0.001$; nd: not detected.

CR6 exhibited multiple hallmarks of human Crohn's disease after dextran sodium sulfate administration compared to mice infected with MNV-1 CW3 [28]. In addition, the observed phenotype is dependent on the timing of infection. In fact, inflammatory hallmarks of Crohn's disease are only observed when a lap of time of 7 days between viral infection and DSS protocol are respected and not when viral infection and DSS protocol are experimented at the same time.

Despite the large number of published studies on MNV, little is known regarding consequences of MNV in infectious models other than the gastrointestinal tract target. Globally, infection in mice is not dramatically altered by MNV. In fact, MNV CR6 did not alter immune responses in C57BL/6 mice co-infected with Friend virus [29], influenza A virus [14], vaccinia virus [14] or murine cytomegalovirus [30]. The effect of murine norovirus $4 \mathrm{Ldlr}$ $\mathrm{KO}$ mouse model of atherosclerosis was found to be dependent on the time of infection [31,32]. Therefore, the analysis of all of these studies highlights the importance of different variables. Indeed, the observed phenotypes are dependent on the MNV strain, murine genetic background, and the timing of infection used in the study.
Since the late twentieth century, infectious diseases rarely affect immunocompetent hosts. The emergence of these diseases that do not infect healthy individuals shows that existing pathogenicity and virulence concepts do not include the host contribution as much as the microorganism in microbial pathogenesis and the resulting symptoms. To remedy this problem, a new theoretical approach to the understanding of microbial pathogenesis known as the "damage-response" was proposed by Casadevall and Pirofski [33]. This theory is based on three principles: the pathogenesis of microbial infections is due to the interaction between the host and the microorganism; the host prognosis is determined by the severity of tissue damage from the host pathogen interaction; induced tissue damage is due to both the pathogen but also the response of the host. Neutrophils play a key role in bacterial clearance but are also implicated in the post-acute lung injury to a bacterial infection. Indeed, the severity of these lesions is dependent on the intensity and duration of the inflammatory process. The role of pro-inflammatory molecules such as TNF- $\alpha$ in bacterial infection is complex contributing to host defence, but also participating in organ damage and
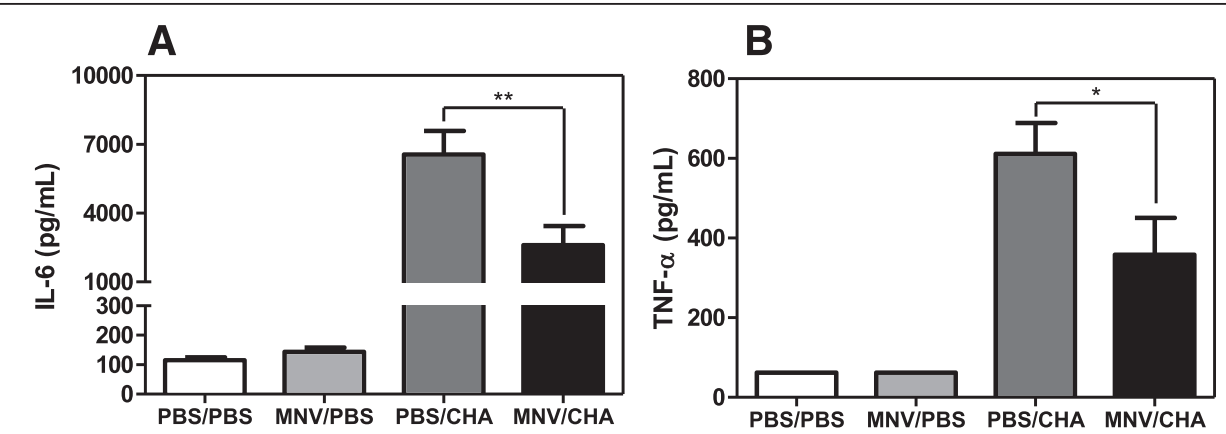

Figure 4 Pro-inflammatory response. WT mice were infected per os with $1.10^{7}$ PFU of MNV or PBS ( $n=10 /$ group). A week later, mice were infected with intranasal instillation of $2.10^{6}$ CFU of $P$. aeruginosa or PBS. A IL-6 and B TNFa protein were measured by ELISA in supernatants of BAL. ${ }^{*}, P<0.05 ;{ }^{* *}, P<0.01 ;{ }^{* * *}, P<0.001$. 
lethality [34]. For example, Kim et al showed that infection with MNV-1 increased lethality induced by secondary infection with $E$. coli, and this was mediated, in part, by TNF- $\alpha$ production [18]. Interestingly, we showed that MNV S99 could modulate the immune response in acute lung infection and decrease mortality. In our previous work the inoculum was comparable but the bacterial infection was performed only $24 \mathrm{~h}$ after the viral infection. Moreover the route for the bacterial infection was also different (intraperitoneal versus intranasal). The main difference is probably related to the timing between the viral and bacterial infection. Recently Kernbauer et al. have shown a protective effect of CR6 and Ski strains of murine norovirus. Indeed, the administration of these strains has improved the survival of mice treated with a cocktail of antibiotics subjected to chemical colitis protocol. In addition, the authors demonstrated that MNV viral infection could provide protection against intestinal lesions induced by C. rodentium [35].

To our knowledge, this is the first report directly testing the effect of MNV S99 on a mouse model of acute lung infection. This study demonstrates unequivocally that MNV modulates the response to Pseudomonas aeruginosa induced lung injury. The S99 strain of murine norovirus led to a reduction in the inflammatory response that is found exaggerated and harmful for mice only infected with the CHA strain of $P$. aeruginosa. Studies have demonstrated that the MNV could disseminate in the organism through the cells it infects. Therefore, the MNV can be found in the lungs and diverting the cellular machinery of the immune cells for replication thereby reducing the immune response. Also, this virus can function in a manner analogous to commensal bacteria and the presence of certain virus strains to be beneficial for the host.

$\mathrm{MNV}$ is a prevalent and endemic virus in research mouse colonies. Our studies suggest that MNV infection can alter the survival and the immune response in a mouse model for acute lung infection. Given the prevalence of MNV in animal facility research, it is now necessary to consider this unwelcomed parameter.

\section{Competing interests}

The authors declare that they have no competing interests.

\section{Authors' contributions}

$M T, K F, E K, R D$ and BG conceived the study. MT, PB and TG performed experiments assisted by P-EL, BG and DH participated in study design and provided critical advice. MT and TG analysed the data and MT wrote the first draft of the manuscript. All authors discussed the results and commented on the manuscript.

\section{Acknowledgements}

We thank B. Toussaint (THeREx, Grenoble) for providing strain of $P$. aeruginosa. We are grateful to other members of D. Hober's Laboratory for technical assistance. We thank T. Chassat and J-P. Decavel for animal breeding logistics. This work was supported by Lille 2 University and CHRU de Lille.

\section{Author details}

'EA 7366: Pseudomonas aeruginosa Host-Pathogen Translational Research Group, UDSL, Université Lille Nord de France, 59045 Lille, France. ${ }^{2}$ Laboratoire de virologie EA3610, Faculté de Médecine, CHRU, Université Lille 2, 59037 Lille, France.

Received: 14 April 2015 Accepted: 11 August 2015

Published online: 04 September 2015

\section{References}

1. Karst SM, Wobus CE, Lay M, Davidson J, Virgin HW (2003) STAT1-dependent innate immunity to a Norwalk-like virus. Science 299:1575-1578

2. Lopman B, Gastañaduy P, Park GW, Hall AJ, Parashar UD, Vinjé J (2012) Environmental transmission of norovirus gastroenteritis. Curr Opin Virol 2:96-102

3. Hsu CC, Riley LK, Wills HM, Livingston RS (2006) Persistent infection with and serologic cross-reactivity of three novel murine noroviruses. Comp Med 56:247-251

4. Müller B, Klemm U, Mas Marques A, Schreier E (2007) Genetic diversity and recombination of murine noroviruses in immunocompromised mice. Arch Virol 152:1709-1719

5. Thackray LB, Wobus CE, Chachu KA, Liu B, Alegre ER, Henderson KS, Kelley ST, Virgin HW (2007) Murine noroviruses comprising a single genogroup exhibit biological diversity despite limited sequence divergence. J Virol 81:10460-10473

6. Barron EL, Sosnovtsev SV, Bok K, Prikhodko V, Sandoval-Jaime C, Rhodes CR, Hasenkrug K, Carmody AB, Ward JM, Perdue K, Green KY (2011) Diversity of murine norovirus strains isolated from asymptomatic mice of different genetic backgrounds within a single U.S. research institute. PLoS One 6:e21435

7. Smith DB, McFadden N, Blundell RJ, Meredith A, Simmonds P (2012) Diversity of murine norovirus in wild-rodent populations: species-specific associations suggest an ancient divergence. J Gen Virol 93:259-266

8. Henderson KS (2008) Murine norovirus, a recently discovered and highly prevalent viral agent of mice. Lab Anim 37:314-320

9. Hsu CC, Wobus CE, Steffen EK, Riley LK, Livingston RS (2005) Development of a microsphere-based serologic multiplexed fluorescent immunoassay and a reverse transcriptase $P C R$ assay to detect murine norovirus 1 infection in mice. Clin Diagn Lab Immunol 12:1145-1151

10. Pritchett-Corning KR, Cosentino J, Clifford CB (2009) Contemporary prevalence of infectious agents in laboratory mice and rats. Lab Anim 43:165-173

11. Kitajima M, Oka T, Takagi H, Tohya Y, Katayama H, Takeda N, Katayama K (2010) Development and application of a broadly reactive real-time reverse transcription-PCR assay for detection of murine noroviruses. J Virol Methods 169:269-273

12. Kim M, Lee H, Chang K-O, Ko G (2010) Molecular characterization of murine norovirus isolates from South Korea. Virus Res 147:1-6

13. Kim JR, Seok SH, Kim DJ, Baek M, Na Y, Han J, Kim T, Park J, Turner PV, Chung DH, Kang B (2011) Prevalence of murine norovirus infection in Korean laboratory animal facilities. J Vet Med Sci 73:687-691

14. Hensley SE, Pinto AK, Hickman HD, Kastenmayer RJ, Bennink JR, Virgin HW, Yewdell JW (2009) Murine norovirus infection has no significant effect on adaptive immunity to vaccinia virus or influenza A virus. J Virol 83:7357-7360

15. Higgins PDR, Johnson LA, Sauder K, Moons D, Blanco L, Taube S, Wobus CE (2011) Transient or persistent norovirus infection does not alter the pathology of Salmonella typhimurium induced intestinal inflammation and fibrosis in mice. Comp Immunol Microbiol Infect Dis 34:247-257

16. Hsu CC, Paik J, Treuting PM, Seamons A, Meeker SM, Brabb TL, Maggio-Price L (2014) Infection with murine norovirus 4 does not alter Helicobacter-induced inflammatory bowel disease in II10(-/-) mice. Comp Med 64:256-263

17. Lencioni KC, Drivdahl R, Seamons A, Treuting PM, Brabb T, Maggio-Price L (2011) Lack of effect of murine norovirus infection on a mouse model of bacteria-induced colon cancer. Comp Med 61:219-226

18. Kim Y-G, Park J-H, Reimer T, Baker DP, Kawai T, Kumar H, Akira S, Wobus C, Núñez G (2011) Viral infection augments Nod1/2 signaling to potentiate lethality associated with secondary bacterial infections. Cell Host Microbe 9:496-507 
19. Chachu KA, Strong DW, LoBue AD, Wobus CE, Baric RS, Virgin HW (2008) Antibody is critical for the clearance of murine norovirus infection. J Virol 82:6610-6617

20. Hamilton MA, Russo RC, Thurston RV (1977) Trimmed Spearman Karber method for estimating median lethal concentrations in toxicity bioassays. Environ Sci Technol 11:714-719

21. Firquet S, Beaujard S, Lobert P-E, Sané F, Caloone D, Izard D, Hober D (2014) Viruses contained in droplets applied on warmed surface are rapidly inactivated. Microbes Environ 29:408-412

22. Mena JA, Ramírez OT, Palomares LA (2003) Titration of non-occluded baculovirus using a cell viability assay. Biotechniques 34:260-264

23. Boutoille D, Marechal X, Pichenot M, Chemani C, Guery B, Faure K (2009) FITC-albumin as a marker for assessment of endothelial permeability in mice: comparison with 125l-albumin. Exp Lung Res 35:263-271

24. Mumphrey SM, Changotra H, Moore TN, Heimann-Nichols ER, Wobus CE, Reilly MJ, Moghadamfalahi M, Shukla D, Karst SM (2007) Murine norovirus infection is associated with histopathological changes in immunocompetent hosts, but clinical disease is prevented by STAT1-dependent interferon responses. J Virol 81:3251-3263

25. Wobus CE, Karst SM, Thackray LB, Chang K-O, Sosnovtsev SV, Belliot G, Krug A, Mackenzie JM, Green KY, Virgin HW (2004) Replication of Norovirus in cell culture reveals a tropism for dendritic cells and macrophages. PLoS Biol 2:e432

26. Jones MK, Watanabe M, Zhu S, Graves CL, Keyes LR, Grau KR, Gonzalez Hernandez MB, lovine NM, Wobus CE, Vinje J, Tibbetts SA, Wallet SM, Karst SM (2014) Enteric bacteria promote human and mouse norovirus infection of B cells. Science 346:755-759

27. Elftman MD, Gonzalez-Hernandez MB, Kamada N, Perkins C, Henderson KS, Núñez G, Wobus CE (2013) Multiple effects of dendritic cell depletion on murine norovirus infection. J Gen Virol 94:1761-1768

28. Cadwell K, Patel KK, Maloney NS, Liu T-C, Ng ACY, Storer CE, Head RD, Xavier R, Stappenbeck TS, Virgin HW (2010) Virus-plus-susceptibility gene interaction determines Crohn's disease gene Atg16L1 phenotypes in intestine. Cell 141:1135-1145

29. Ammann CG, Messer RJ, Varvel K, Debuysscher BL, Lacasse RA, Pinto AK, Hasenkrug KJ (2009) Effects of acute and chronic murine norovirus infections on immune responses and recovery from Friend retrovirus infection. J Virol 83:13037-13041

30. Doom CM, Turula HM, Hill AB (2009) Investigation of the impact of the common animal facility contaminant murine norovirus on experimental murine cytomegalovirus infection. Virology 392:153-161

31. Paik J, Fierce Y, Mai P, Phelps SR, Mcdonald T, Treuting P, Drivdahl R, Brabb T, Leboeuf R, Brien KDO, Maggio-price L (2011) Murine Norovirus Increases Atherosclerotic Lesion Size and Macrophages in Ldlr - / - Mice. Comp Med 61:330-338

32. Paik J, Kwok F, Seamons A, Brabb T, Kim J, Sullivan B, Hsu C, O'Brien KD, Maggio-Price $L$ (2015) Effects of murine norovirus on atherosclerosis in Idr(-/-) mice depends on the timing of infection. Comp Med 65:114-122

33. Casadevall A, Pirofski LA (2000) Host-pathogen interactions: Basic concepts of microbial commensalism, colonization, infection, and disease. Infect Immun 68:6511-6518

34. Beutler B, Milsark IW, Cerami AC (1985) Passive immunization against cachectin/tumor necrosis factor protects mice from lethal effect of endotoxin. Science 229:869-871

35. Kernbauer E, Ding Y, Cadwell K (2014) An enteric virus can replace the beneficial function of commensal bacteria. Nature 516:94-98

\section{Submit your next manuscript to BioMed Central and take full advantage of:}

- Convenient online submission

- Thorough peer review

- No space constraints or color figure charges

- Immediate publication on acceptance

- Inclusion in PubMed, CAS, Scopus and Google Scholar

- Research which is freely available for redistribution 